\title{
BASIC SPECIFICATION REGARDING THE WIND POWER SYSTEMS CONTROL
}

\author{
Horia Ciocarlie, Florica Balog, Gheza-Mihai Erdodi, Marius Babescu \\ Polytechnic University/Department of Computer Science, Timisoara, Romania \\ horia.ciocarlie@cs.upt.ro \\ Polytechnic University/Department of Computer Science, Timisoara, Romania \\ florica.novacescu@gmail.com \\ Polytechnic University/Department of Electrical Engineering, Timisoara, Romania \\ geza.erdodi@erlendieselservice.ro \\ Polytechnic University/Department of Electrical Engineering, Timisoara, Romania \\ marius.babescu@upt.ro
}

\section{ABSTRACT}

\begin{abstract}
The paper proposes an original metod to control the wind power system at variable wind speed. In the case of those high power wind systems that presents large inertia moments due to the variable wind speed, the rotation speed of both wind turbine and permanent magnet synchronous generator can not be modified in a timely manner so as to ensure the turbine operating in maximum power points. Therefore, the paper presents two control structures. First structure is based on the load calculation of permanent magnet synchronous generator and the second is based on the load modifying by using controllers. The rotation speed of turbine estimation has been used as reference in the both structures.
\end{abstract}

\section{Indexing terms/Keywords}

Mathematical model, variable wind speed, mechanical inertia, rotation speed estimation, maximum energy.

\section{Council for Innovative Research}

Peer Review Research Publishing System

Journal: INTERNATIONAL JOURNAL OF COMPUTERS \& TECHNOLOGY

Vol 12, No. 9

editor@cirworld.com

www.cirworld.com, www.ijctonline.com 


\section{INTRODUCTION}

The wind speed ranges as in (1), and the best results are achieved, into the technical- economical working domain, for the interval $12 \div 15 \mathrm{~m} / \mathrm{s}$.

$V=4 \div 25[\mathrm{~m} / \mathrm{s}]$

The wind power systems are controled by considering the average wind speed [8-17]. Recently, control structures based on measuring the instantaneous wind speed [1-5] were proposed, and they use suitable mathematical model for the wind turbine.

In the case of wind power systems operation due to time variation of wind speed, a lot of important issues occure, they are the following:

1. load generator determination is perform in order to accomplish the maximum of captured energy for a long time period (days);

2. most efficient control methods determination from the both technical and economical points of view;

3. some real mathematical models determination for wind turbine and electrical generator (generator that usually has permanent magnets);

4. boundaries establishing between to fit the initial conditions, (regarding speed and load of the generator) in the case of electrical network plugging, is achieved by simulation;

5. establishing the quality of base duty cycles for different control structures shall be determined by simulation.

In the most works $[1,21]$ the control methods at full power are proposed, which may result in a shutdown of the turbine because the artificially increased power is not obtained from the wind, but from the kinetic energies variation of rotating masses. Considering this reason, it is more fair to operate at maximum energy obtained in a large time interval, by the order of days. Thus, it is necessary to determine the speed of generator (RPM or reference angular speed), so that the energy captured by the wind turbine reach the maximum value, taking in to account that the wind speed varies significantly in time.

The RPM reference value can be achieved by various methods:

- requiring the generator load resistance that is calculated by using the mathematical models of both wind turbine, permanent magnet sincronus generator and by measuring the wind speed, as well;

- using controllers that modify the generator load in order to obtain the reference speed.

At certain values of the controller constants, override and instability occur in the case of controller adjusting. If the dependence of reference angular speed by the wind speed is given by the manufacturing company of turbine, these situations can be avoided.

The load resistance of generator can be calculated and the wind system, which consists of wind turbine coupled to permanent magnet synchronous generator, works in optimum energy parameters, if the reference angular speed is known.

RPM modification of the generator is slowly due to the very high inertia momentums of wind turbine and it can not follow a fast variation of the wind speed, as required to operate in the maximum power points [1], [3], [15].

\subsection{Specifications}

1. Due to the high mechanical inertia, the simulations and all the other theoretical and practical results must have intervals of at least several days (typically more than 10[h]).

2. The best control systems should provide the maximum wind energy captured in a long time interval.

3. The wind system control at maximum power obtained from the electrical generator leads to turbine braking and, also, to the artificially power increasing for the moment. This artificially power increasing is not obtained from wind, but from the kinetic energies variation of rotating masses. But in the end, after a long time period, the obtained energy is less than the previous case.

4. On the other hand, the control of wind system at the maximum energy, which is achieved from the electric generator, is the right solution from technical and economical point of view and it requires estimating the fundamental quantities-dependent by the wind speed, such as: wind turbine RPM, current intensity or generator load resistance.

Optimum control of wind system involves capturing the maximum energy at variable wind speed. This requires both RPM and torque control of the turbine, and also adapting the generator load to the wind speed.

Within the sampling interval $\Delta t$, the electrical generator has to take both the maximum available wind energy and the kinetic energies difference of rotating masses, and the real RPM of the generator goes to the reference RPM (optimal RPM). 
On the interval $\Delta t$ and at $V(t)$ wind speed, the maximum available wind energy is achieved by taking the RPM (the reference speed) and the variations of kinetic energies and increasing (or decreasing) the additional load of the electrical generator.

The wind system works optimally (at the maximum energy) when the wind turbine (TV) has the maximum possible energy in a given time interval, by the order of days.

\section{MATHEMATICAL MODELS}

\subsection{Mathematical model of wind turbine}

The experimental mechanical characteristic of wind turbine is given by an analytical function whose characteristics passes through the experimental points, as shown in figure 1, [3].

An original model of wind turbine is considered, the model allows estimating the optimum reference angular speed $\omega_{\text {ref. }}$

Equation (2) represents the proposed analytical expression of the wind turbine torque that is reduced to the generator shaft.

$M_{T V}=A \cdot \sin \left(\frac{\omega}{V} \cdot B\right)$

where $A$ and $B$ are achieved by the experimental mechanical characteristics, $V$ is the wind speed, and $\omega$ is the mechanical angular speed.

Figure 1 shows the experimental mechanical characteristics for the wind speeds $V=8.6[\mathrm{~m} / \mathrm{s}], 6.3[\mathrm{~m} / \mathrm{s}]$ and $4[\mathrm{~m} / \mathrm{s}]$.

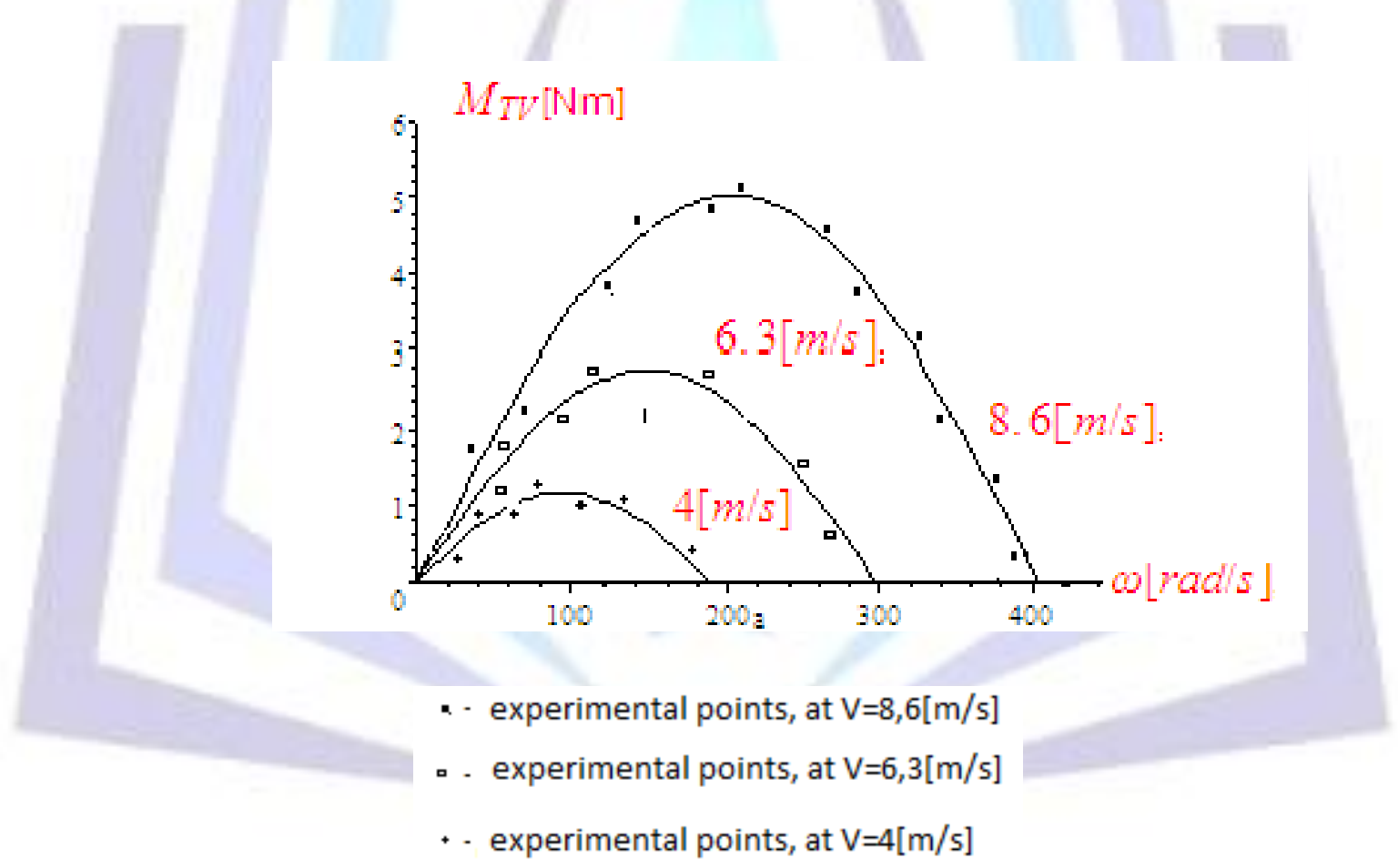

Fig 1: The experimental mechanical characteristics

The value of mechanical characteristic $\left(\mathrm{MTV}_{\mathrm{TV}}(\omega)\right)$ is obtained by using (3).

$M_{T V}=11 \cdot\left(\frac{V}{13}\right)^{1.9} \cdot \sin \left(\frac{\omega_{G E}}{V} \cdot 6.6666 \cdot 10^{-2}\right)$

Figure 2 shows the mechanical characteristics (shaded area) obtained in the case of wind speed ranging between $\mathrm{V}_{\mathrm{MAX}}=8.6[\mathrm{~m} / \mathrm{s}]$ and $\mathrm{V}_{\mathrm{MIN}}=4[\mathrm{~m} / \mathrm{s}]$. For the average wind speed $\left(\mathrm{V}_{\mathrm{MEDIE}}=(8.6+4) / 2=6.3[\mathrm{~m} / \mathrm{s}]\right)$, the mechanical characteristic, represented by dotted line, is accomplished.

The reference mechanical-angular speed $\left(\omega_{\text {ref }}\right)$ calculated by using the instantaneous values of wind speed is $\omega_{\text {ref } 1}^{*}$ and the one calculated by using the average value of wind speed is $\omega_{r e f 2}^{*}$. The values are different, as seen in figure 2. 
For $\omega=\omega_{\text {ref } 1}^{*}$ and $\mathrm{V}=\mathrm{V}_{\mathrm{MAX}}=8.6[\mathrm{~m} / \mathrm{s}]$ the operating point is $\mathrm{P}_{1}$. At $\omega=\omega_{\text {ref } 2}^{*}$ and $\mathrm{V}=\mathrm{V}_{\mathrm{MEDIE}}=6.3[\mathrm{~m} / \mathrm{s}]$ the operating point is $P_{2}$ and for $V=V_{M I N}=4[m / s]$ the operating point is $P_{3}$.

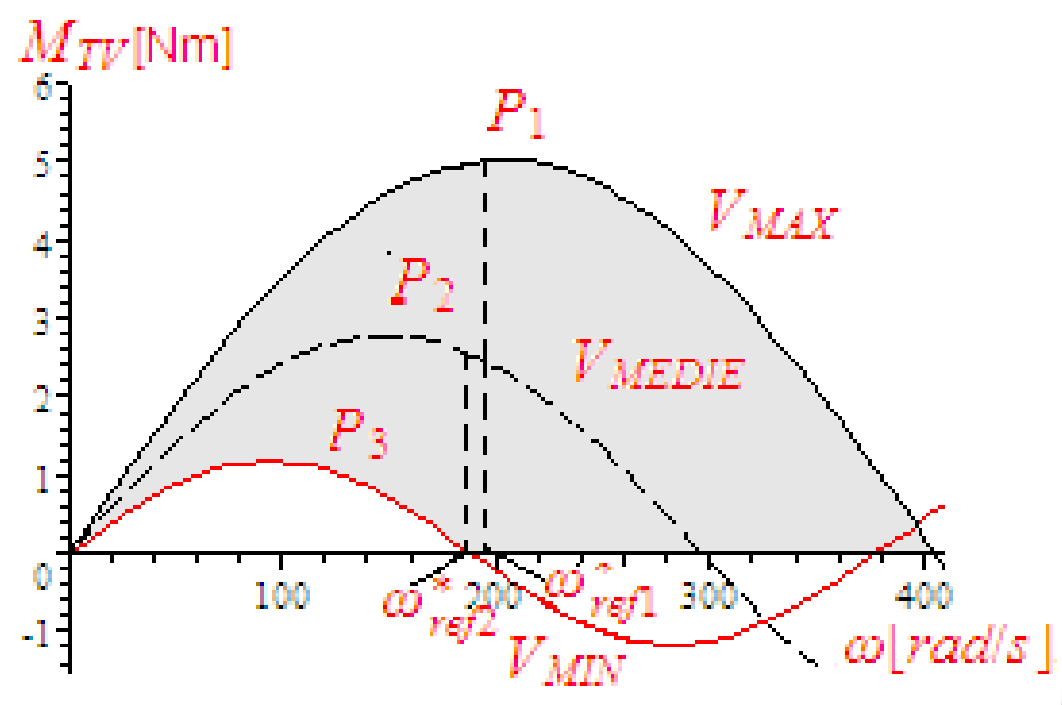

Fig 2: The mechanical characteristics at $\mathrm{V}_{\mathrm{MAX}}=8.6[\mathrm{~m} / \mathrm{s}]$ and $\mathrm{V}_{\mathrm{MIN}}=4[\mathrm{~m} / \mathrm{s}]$

Figure 3 gives the power characteristics for $\mathrm{VMAX}=8.6[\mathrm{~m} / \mathrm{s}]$ and $\mathrm{VMIN}=4[\mathrm{~m} / \mathrm{s}]$.

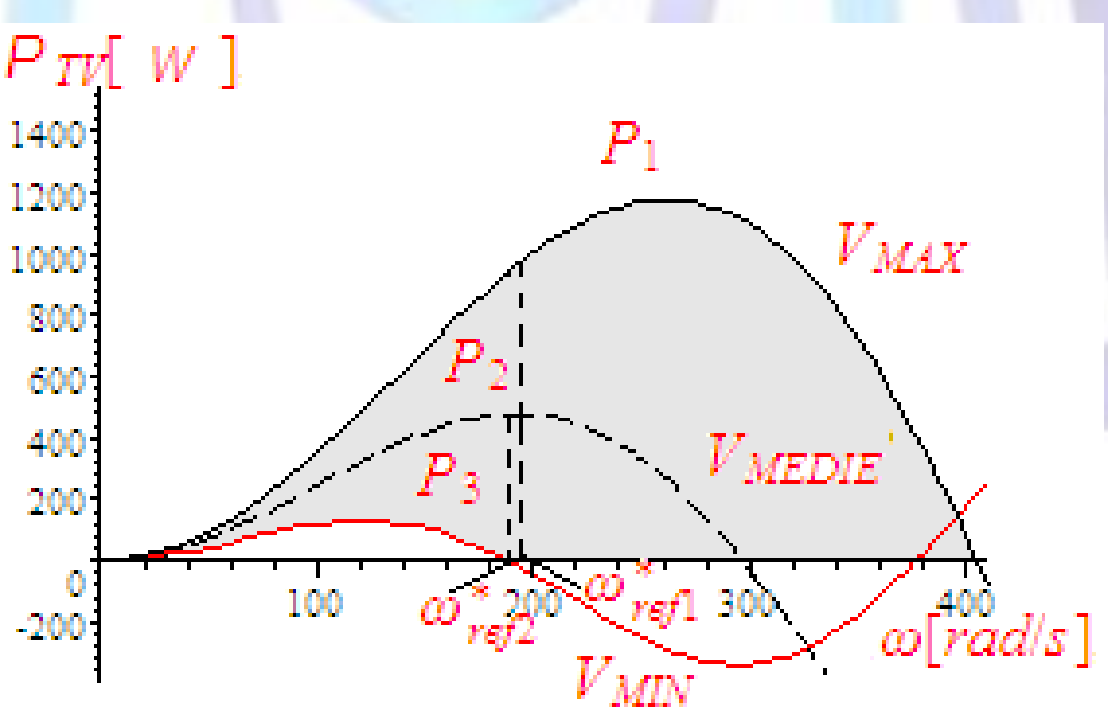

Fig 3: The power characteristics at $\mathrm{V}_{\mathrm{MAX}}=8.6[\mathrm{~m} / \mathrm{s}]$ and $\mathrm{V}_{\mathrm{MIN}}=4[\mathrm{~m} / \mathrm{s}]$

\subsection{Mathematical model of wind speed}

If the real variation of wind speed has the form shown in figure 4, where $\mathrm{V}$ can be considered having a sinusoidal evolution of $\mathrm{T}=35[\mathrm{~s}]$ time period. The period of the wind speed variation between $\mathrm{V}_{\mathrm{MAX}}=8.6[\mathrm{~m} / \mathrm{s}]$ and $\mathrm{V}_{\mathrm{MIN}}=4[\mathrm{~m} / \mathrm{s}]$ is determined considering the real speed measurement and it is given in figure 4 . 


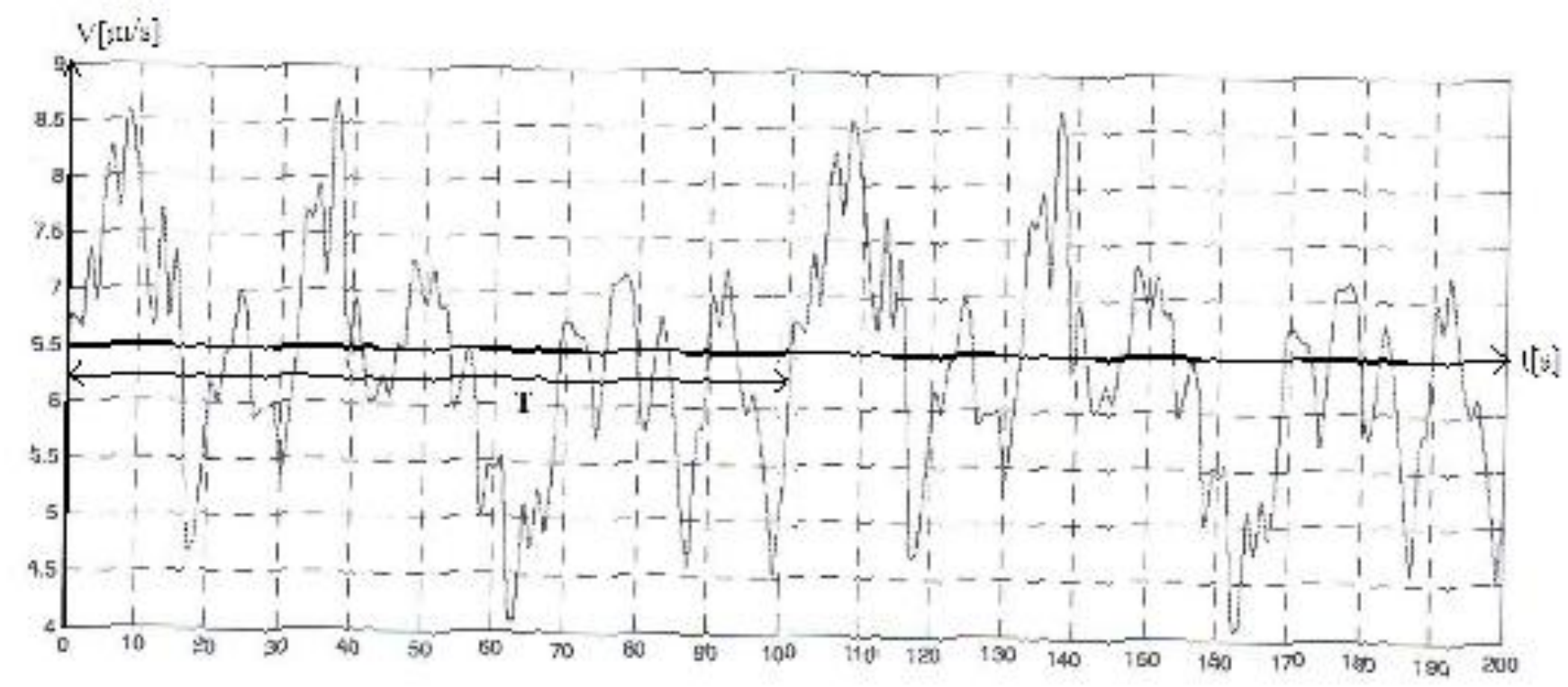

Fig 4: The real variation of wind speed

The average speed, which is $\mathrm{V}_{\mathrm{MEDIE}}=6.3[\mathrm{~m} / \mathrm{s}]$, can be expressed in another form by using (4), it is shown in figure 5 .

$$
V(t)=V_{\text {MEDIE }}+2.3 \cdot \sin (2 \cdot \pi / T)=6.3+2.3 \cdot \sin 0.17943 t
$$

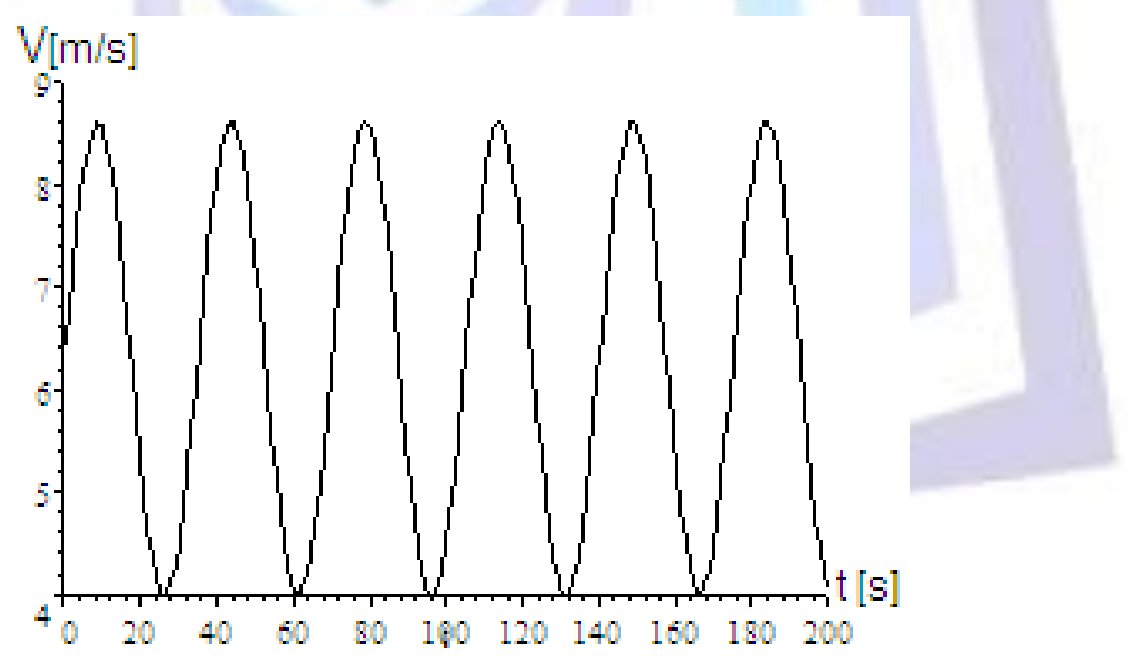

Fig 5: The modeled wind speed

If the generator speed is assumed as being constant (having a certain value), and the wind speed has a sinusoidal variation, the issue is to determine the RPM of generator so that the captured energy, by the wind turbine (TV) in the time $T$, to be maximal.

\subsubsection{Specifications}

The maximum power point $P_{M A X 1}$ of wind turbine has the coordinates $\left(\omega_{M 1}, P_{M 1}\right)$ at $V_{M I N}$ wind speed, while $P_{M A X 2}$ has the coordinates $\left(\omega_{\mathrm{M} 2}, \mathrm{P}_{\mathrm{M} 2}\right)$ at $\mathrm{V}_{\mathrm{MAX}}$ wind speed.

The maximum power of wind turbine depends on the wind speed caracteristic, as in (5). 


$$
P_{\text {MAX }}=K \cdot V^{3}
$$

Therefore, in the analyzed case of minimum wind speed $\mathrm{V}_{\mathrm{MIN}}=4[\mathrm{~m} / \mathrm{s}]$ and maximum $\mathrm{V}_{\mathrm{MAX}}=8.6[\mathrm{~m} / \mathrm{s}]$, the maximum power given by wind turbine has the following values:

$$
\begin{aligned}
& P_{M A X 1}=K \cdot 4^{3}=K \cdot 64[W] \text { at } \mathrm{V}_{\mathrm{MIN}}=4[\mathrm{~m} / \mathrm{s}] \\
& P_{M A X 2}=K \cdot 8.6^{3}=K \cdot 636.06[W] \text { at } \mathrm{V}_{\mathrm{MAX}}=8.6[\mathrm{~m} / \mathrm{s}]
\end{aligned}
$$

Figure 6 shows the power dependence by $\omega$, at $\mathrm{V}_{\mathrm{MIN}}=4[\mathrm{~m} / \mathrm{s}]$ and $\mathrm{V}_{\mathrm{MAX}}=8.6[\mathrm{~m} / \mathrm{s}]$.

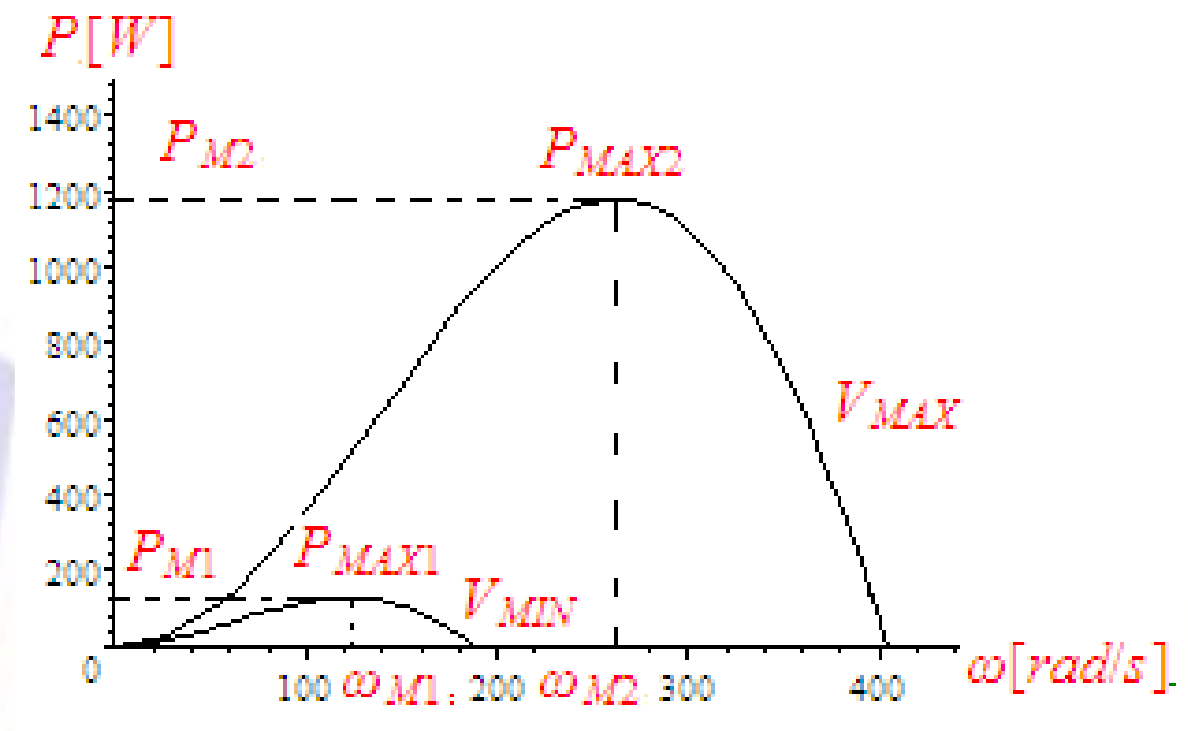

Fig 6: The power dependence by $\omega$, at $\mathrm{V}$ as parameter

To operate in the maximum power points $\left(P_{M A X 1}\right.$ and $\left.P_{M A X 2}\right)$ and, respectively at $\omega_{M 1}=121[\mathrm{rad} / \mathrm{s}]$ and $\omega_{M 2}=261[\mathrm{rad} / \mathrm{s}]$, from the movement equation given in (6), at $\mathrm{J}=50\left[\mathrm{~kg}^{*} \mathrm{~m} 2\right], \mathrm{d} \omega=261-121=140[\mathrm{rad} / \mathrm{s}], \mathrm{dt}=10$ [s] (from the time variation of wind speed shown in figure 4), the movement equation becomes (7).

$$
\begin{aligned}
& M_{T V}-M_{G}=J \cdot \frac{d \omega}{d t} \\
& M_{T V}-M_{G}=50 \cdot \frac{140}{10}=700[\mathrm{Nm}]
\end{aligned}
$$

Since, usual $\mathrm{M}_{\mathrm{TV}}$ and $\mathrm{M}_{\mathrm{G}}$ have values in the field $0 \div 6[\mathrm{Nm}], M_{T V}-M_{G}=700[\mathrm{Nm}]$ can not be achieved, it could be concluded that the wind power system can not operate in the maximum power points. They being unable to work in the maximum power points, the problem is to determine the turbine RPM, so that the wind system to reach the maximum energy in a time period, by the order of days.

\subsection{Mathematical model of the permanent magnet synchronus generator}

In the current applications of wind systems, because the processes are slowly and possess high mechanical inertia, the simplified orthogonal model is used for the electrical generator. This model is given in [3].

For a wind system having the power $\mathrm{P}=5 \mathrm{KW}$, the parameters of generator are the following:

$\mathrm{R}=1.6[\Omega]$

$\mathrm{L}_{d}=0.07[\mathrm{H}]$

$\mathrm{L}_{\mathrm{q}}=0.08[\mathrm{H}]$

$\Psi_{\mathrm{M}}=1.3[\mathrm{~Wb}]$ 


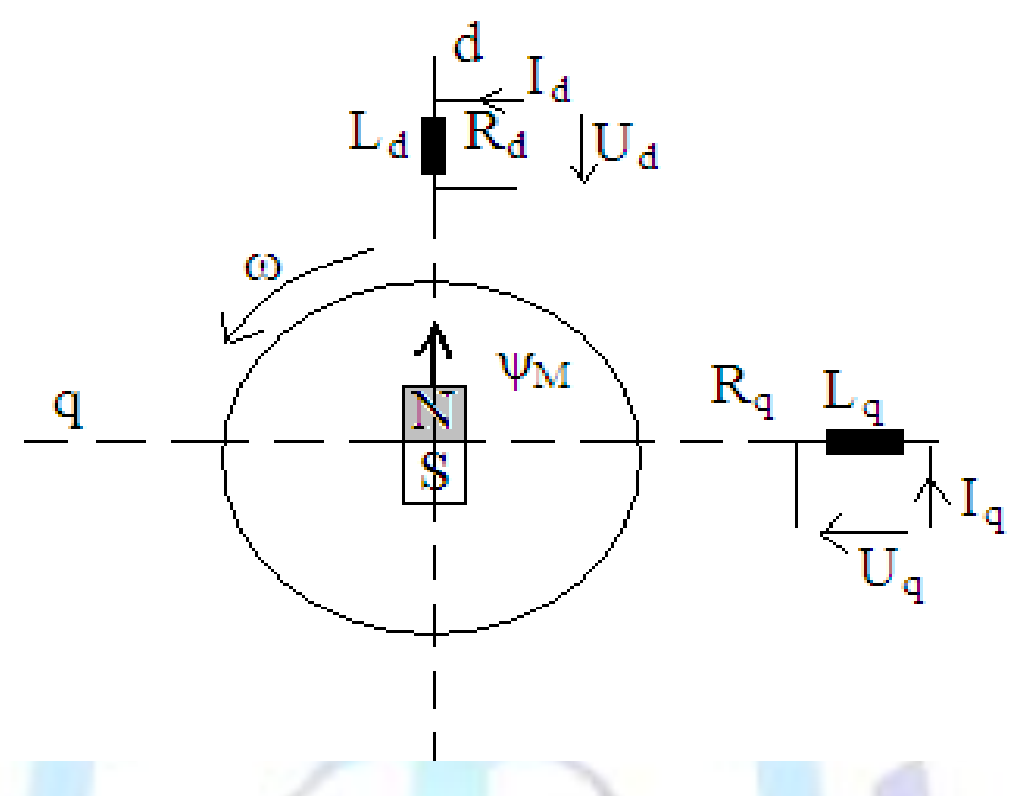

Fig 7: Orthogonal model of the permanent magnet synchronous generator

In case of stady-state, the algebraic system from (8) for the permanent magnet synchronous generator is used.

$$
\left\{\begin{array}{l}
-U \cdot \sqrt{3} \cdot \sin (\theta)=R_{1} \cdot I_{d}-\omega \cdot L_{q} \cdot I_{q} \\
U \cdot \sqrt{3} \cdot \cos (\theta)=R_{1} \cdot I_{q}+\omega \cdot L_{d} \cdot I_{d}+\omega \cdot \Psi_{M} \\
M_{P M S G}=p_{1} \cdot\left(L_{d}-L_{q}\right) \cdot I_{d} \cdot I_{q}+I_{q} \cdot \Psi_{M}
\end{array}\right.
$$

where $M_{P M S G}=M_{G}$ is the generator torque, $R_{1}$ is stator winding resistance, $L_{d}$ is the inductance of the stator winding on the $d$ axis, $L_{q}$ is the inductance of the stator winding on the $q$ axis, $p_{1}$ is the number of pole pairs, and $\psi_{M}$ is permanent magnet flux.

\subsubsection{Determining the generator load}

The issue consists in determining the generator load, so that the RPM to oscillate around the optimum value.

By using (6), and integrating over a time period $\mathrm{T}$, it is obtained:

$\int_{0}^{T} M_{T V} \cdot d t-\int_{0}^{T} M_{G} \cdot d t=J \cdot\left(\omega_{\text {final }}-\omega_{\text {initial }}\right)$

For $\omega_{\text {final }}=\omega_{\text {initial }}$ is obtained:

$\int_{0}^{T} M_{T V} \cdot d t-\int_{0}^{T} M_{G} \cdot d t=0$

At the instantaneous wind speed $V(t)=6.3+2.3 \cdot \sin 0.17943 t, \omega_{r e f 1}^{*}=197.92[\mathrm{rad} / \mathrm{s}]$ was obtained.

If $M_{G}=c t$ it results that: $M_{G}=M_{T V \text {-mediu }}=\frac{1}{T} \int_{0}^{T} M_{T V} \cdot d t$, at this value of average torque, the load resistance $R=138.83[\Omega]$. 


\section{CONTROL OF THE WIND SYSTEM}

If the reference mechanical angular speed $\left(\omega_{\text {ref }}\right)$ is known, the reference load rezistance of generator can be determined. If the reference rezistance $(R=138.83[\Omega])$ is known, the wind system control can be achieved in two ways:

- the load resistance has a prescribed value;

- the load resistance is modified by controllers.

\subsection{First case - The load resistance has a prescribed value}

The mechanical angular speed $\omega_{\text {ref } 1}^{*}=197.92[\mathrm{rad} / \mathrm{s}]$ was calculated using $V(t)=6.3+2.3 \cdot \sin 0.17943 t$. For this value of mechanical angular speed $\omega_{\text {ref } 1}^{*}$, the load resistance has a prescribed value $R=138.83[\Omega]$. Considering these results, figure 8 shows the time variation of $\omega$ for $\omega(0)=177.92[\mathrm{rad} / \mathrm{s}]$, and in figure 9 is shown the time variation of $\omega$ for $\omega(0)=277.92[\mathrm{rad} / \mathrm{s}$.

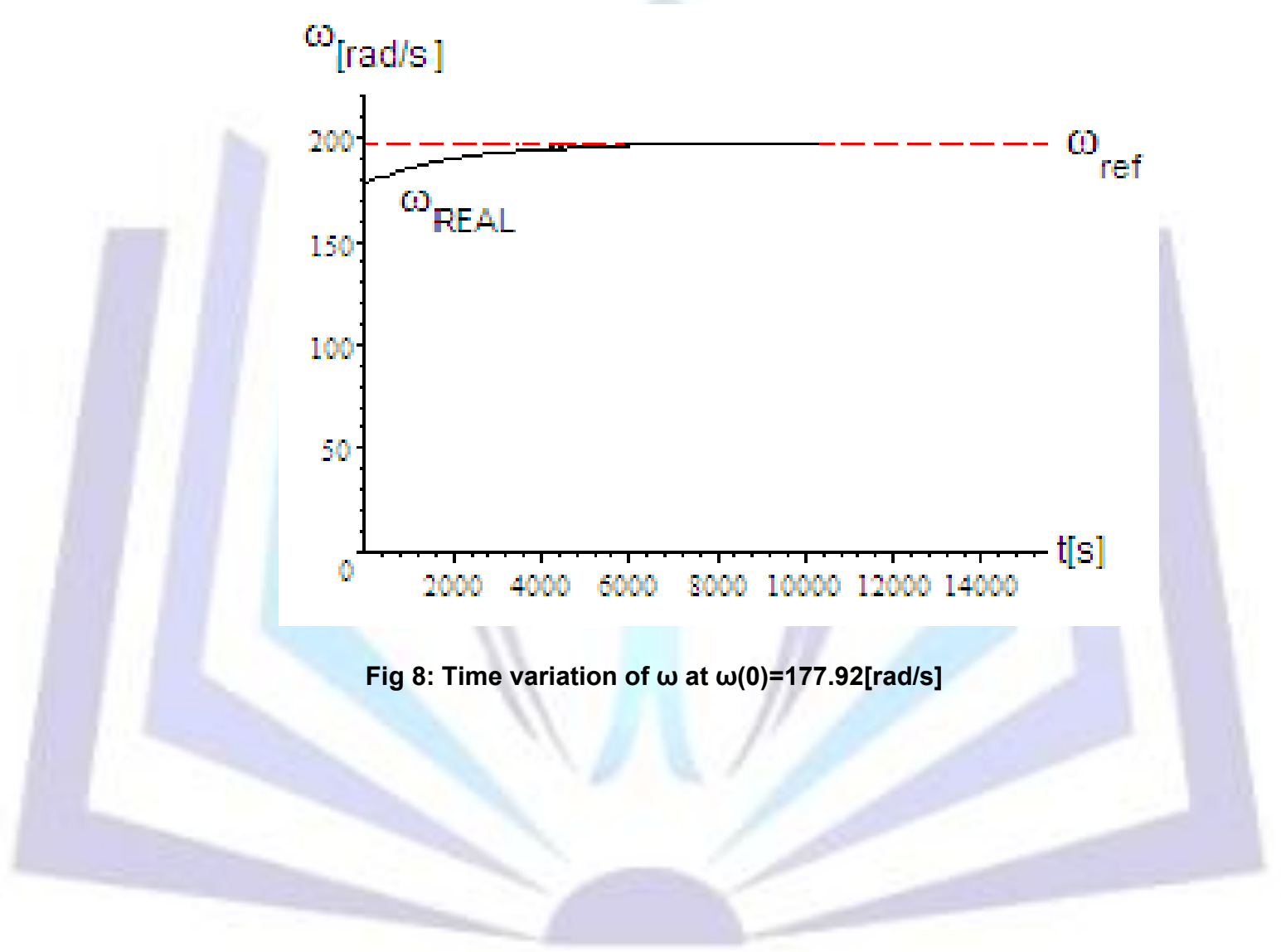




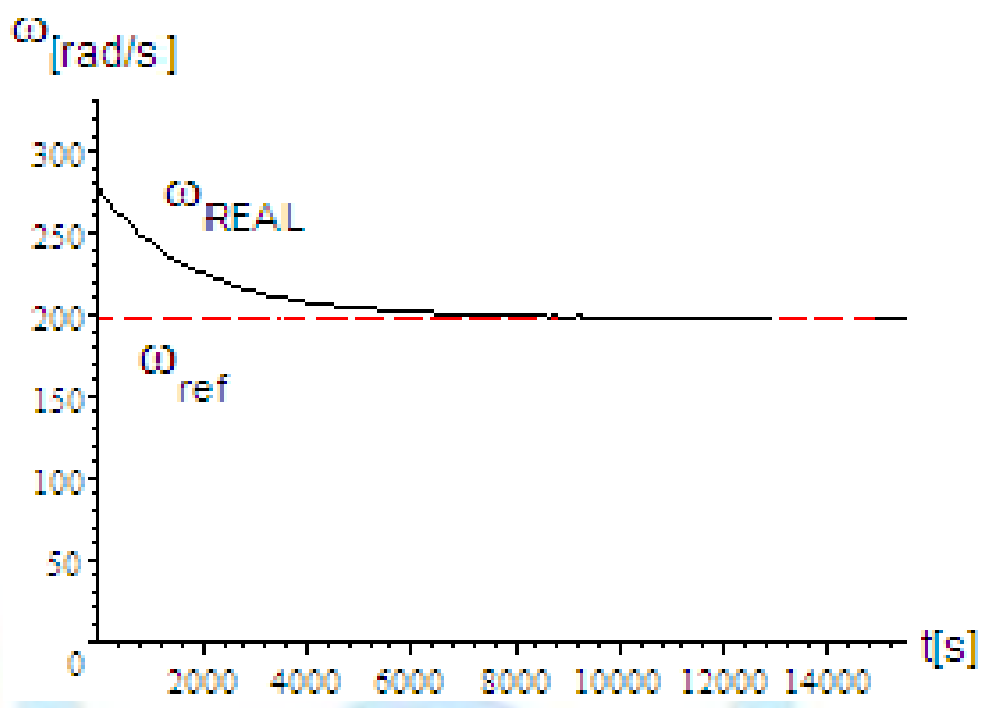

Fig 9: Time variation of $\omega$ at $\omega(0)=277.92[\mathrm{rad} / \mathrm{s}]$

\subsection{Modifying the load using controllers}

\subsection{1. $\mathrm{P}$ controller}

The equation of $\mathrm{P}$ controller is given in (9)

$\Delta R=K_{1} \cdot \Delta \omega=4.5064 \cdot 10^{-2} \cdot\left(\omega-\omega_{\text {ref }}^{*}\right)$

(9)

Equation (9) could be written as the following:

$R=R^{*}+4.5064 \cdot 10^{-2} \cdot\left(\omega-\omega_{r e f}^{*}\right)$

The proportionality constant has the value: $K_{1}=4.5064 \cdot 10^{-2}$.

For the angular speed $\omega_{r e f 1}^{*}=197.92[\mathrm{rad} / \mathrm{s}]$ and $R^{*}=138.83[\Omega]$, the equation of $P$ controller is $R=138.83+4.5064 \cdot 10^{-2} \cdot(\omega-197.92)$ and the time variation of $\omega$, for both $\omega(0)>>\omega_{\text {ref } 1}^{*}$ and $\omega(0)<<\omega_{\text {ref } 1}^{*}$, is achieved by using the motion equation. 


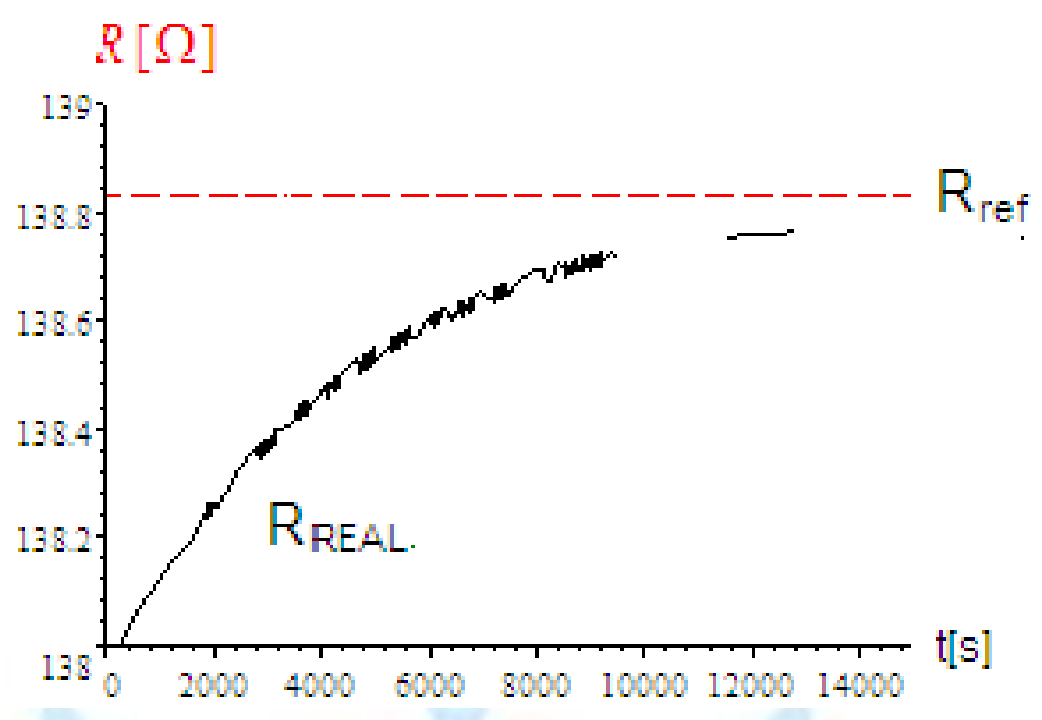

Fig 10: Time variation of $R$ at $\omega(0)=177.92[\mathrm{rad} / \mathrm{s}]$

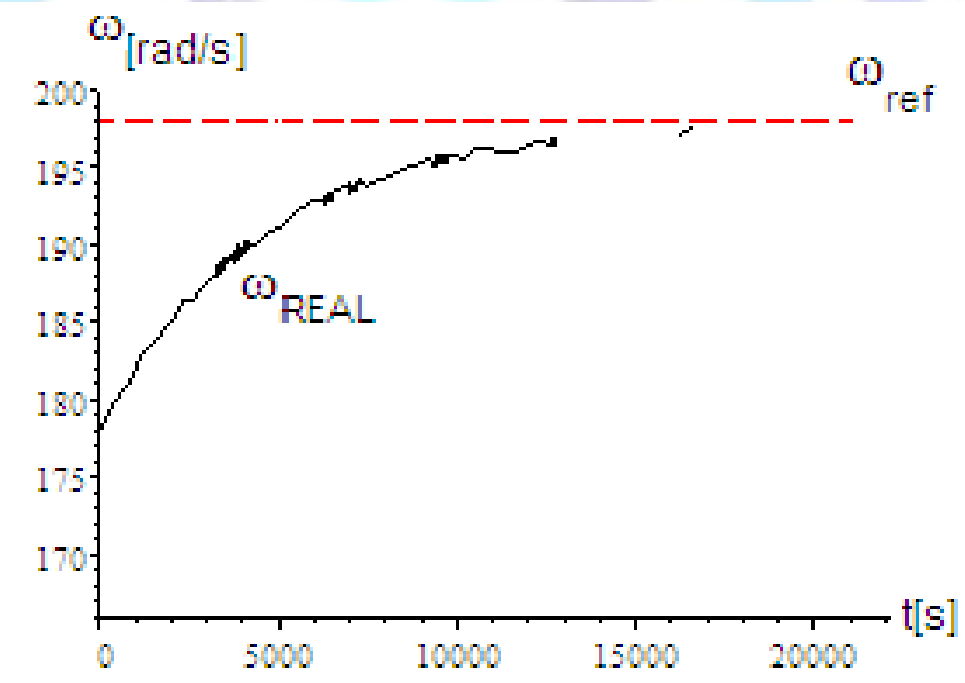

Fig 11: Time variation of $\omega$ at $\omega(0)=177.92[\mathrm{rad} / \mathrm{s}]$ 


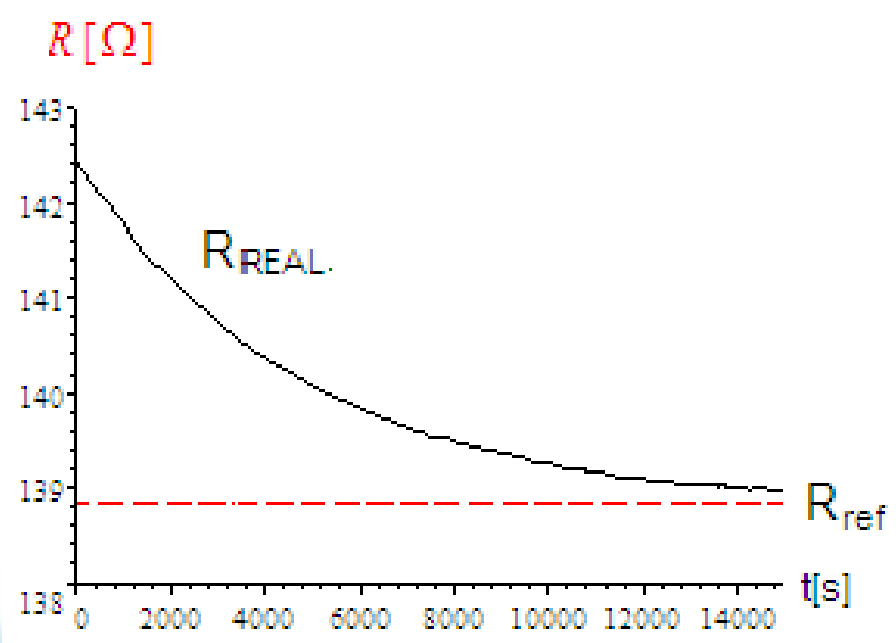

Fig 12: Time variation of $R$ at $\omega(0)=277.92[\mathrm{rad} / \mathrm{s}]$

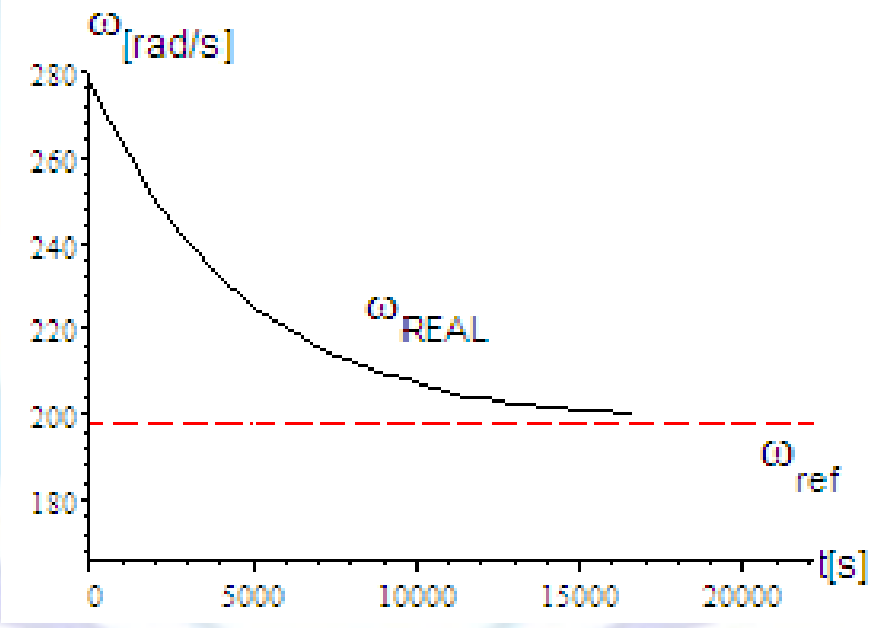

Fig 13: Time variation of $\omega$ at $\omega(0)=277.92[\mathrm{rad} / \mathrm{s}]$

\subsubsection{PI controller (the mechanical angular speed $\omega$ has a prescribed value)}

The $\mathrm{PI}$ controller equation is given in (10).

$\Delta R=K_{1} \cdot \Delta \omega+K_{2} \int \Delta \omega \cdot d t=K_{1} \cdot\left(\omega-\omega_{r e f}\right)+K_{2} \int\left(\omega-\omega_{\text {ref }}\right) \cdot d t$

or:

$\frac{d R}{d t}=K_{1} \cdot \frac{d \omega}{d t}+K_{2} \cdot\left(\omega-\omega_{r e f}\right)$

The proportionality constant has the value: $K_{1}=4.5064 \cdot 10^{-2}$.

Thus, the $\mathrm{PI}$ controller equation is the following:

$\frac{d R}{d t}=4.5064 \cdot 10^{-2} \cdot \frac{d \omega}{d t}+K_{2} \cdot\left(\omega-\omega_{r e f}\right)$ 
For the variable wind speed having the form $V(t)=6.3+2.3 \cdot \sin 0.17943 t$ is obtained the reference mechanical angular speed $\omega_{r e f 1}^{*}=197.92[\mathrm{rad} / \mathrm{s}]$.

The controller constants determination ( $\mathrm{K} 1$ and $\mathrm{K} 2$ ) is done by following analysis of the below simulations.

The movement equation and the PI controller equation form a system of differential equations. This system models the behavior of anssembly and consists of wind turbine and permanent magnet synchronous generator.

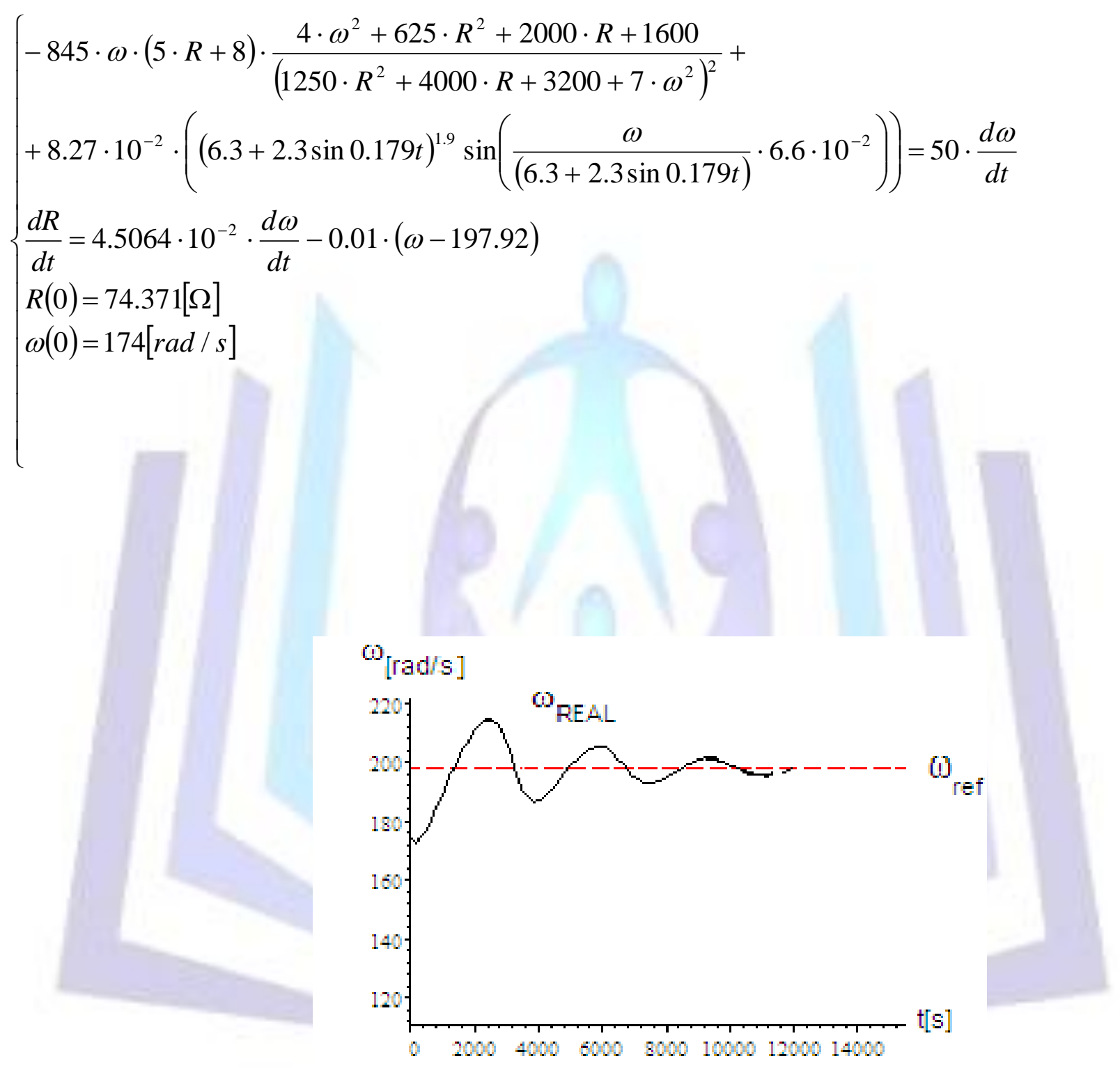

Fig 14: Time variation of $\omega$ at $\omega(0)=174[\mathrm{rad} / \mathrm{s}]$ and $R(0)=74.371[\Omega]$ 


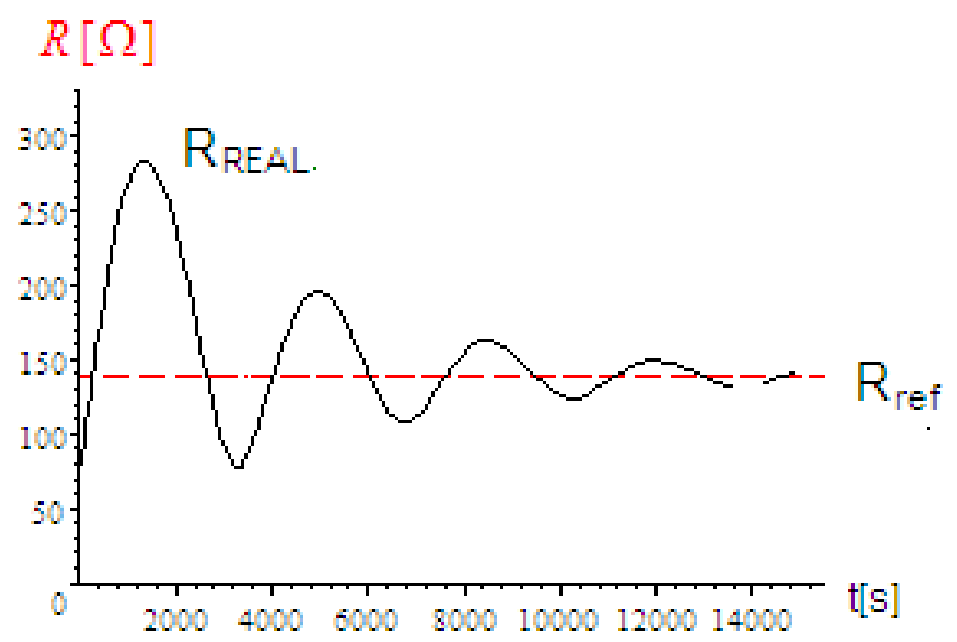

Fig 15: Time variation of $R$ at $\omega(0)=174[\mathrm{rad} / \mathrm{s}]$ and $R(0)=74.371[\Omega]$

\subsubsection{PD controller (the mechanical angular speed $\omega$ has a prescribed value)}

The PD controller equation is given in (11).

$$
\Delta R=K_{1} \cdot \Delta \omega+K_{3} \cdot \frac{d \Delta \omega}{d t}=K_{1} \cdot\left(\omega-\omega_{\text {ref }}\right)+K_{3} \cdot \frac{d\left(\omega-\omega_{\text {ref }}\right)}{d t}
$$

or:

$$
R=R_{r e f}+K_{1} \cdot\left(\omega-\omega_{r e f}\right)+K_{3} \cdot \frac{d \omega}{d t}
$$

At $K_{1}=4.5064 \cdot 10^{-2}$ and $\omega_{r e f 1}^{*}=197.92[\mathrm{rad} / \mathrm{s}]$, another form of PD controller equation is obtained:

$$
R=R_{r e f}+4.5064 \cdot 10^{-2} \cdot(\omega-197.92)+K_{3} \cdot \frac{d \omega}{d t}
$$

3.2.3.1. Generator load determination by using $M_{G}=2.809 \frac{\omega}{R}$ (the simplified model)

At the instantaneous wind speed $V(t)=6.3+2.3 \cdot \sin 0.17943 t$, the reference mechanical angular speed $\omega_{r e f 1}^{*}=197.92[\mathrm{rad} / \mathrm{s}]$ is obtained. For $\mathrm{M}_{\mathrm{G}}=\mathrm{ct}$ it is obtained: $M_{G}=M_{T V \text {-mediu }}=\frac{1}{T} \int_{0}^{T} M_{T V} \cdot d t$. For this value of the average torque, the load resistance $\mathrm{R}=235.64[\Omega]$ for $M_{G}=2.809 \frac{\omega}{R}$ is obtained, by the following system: $\left\{\begin{array}{l}M_{G}=-2.809 \cdot \frac{\omega}{R} \\ \omega=197.92 \\ M_{G}=-2.3594 \\ R=235.64\end{array}\right.$ 


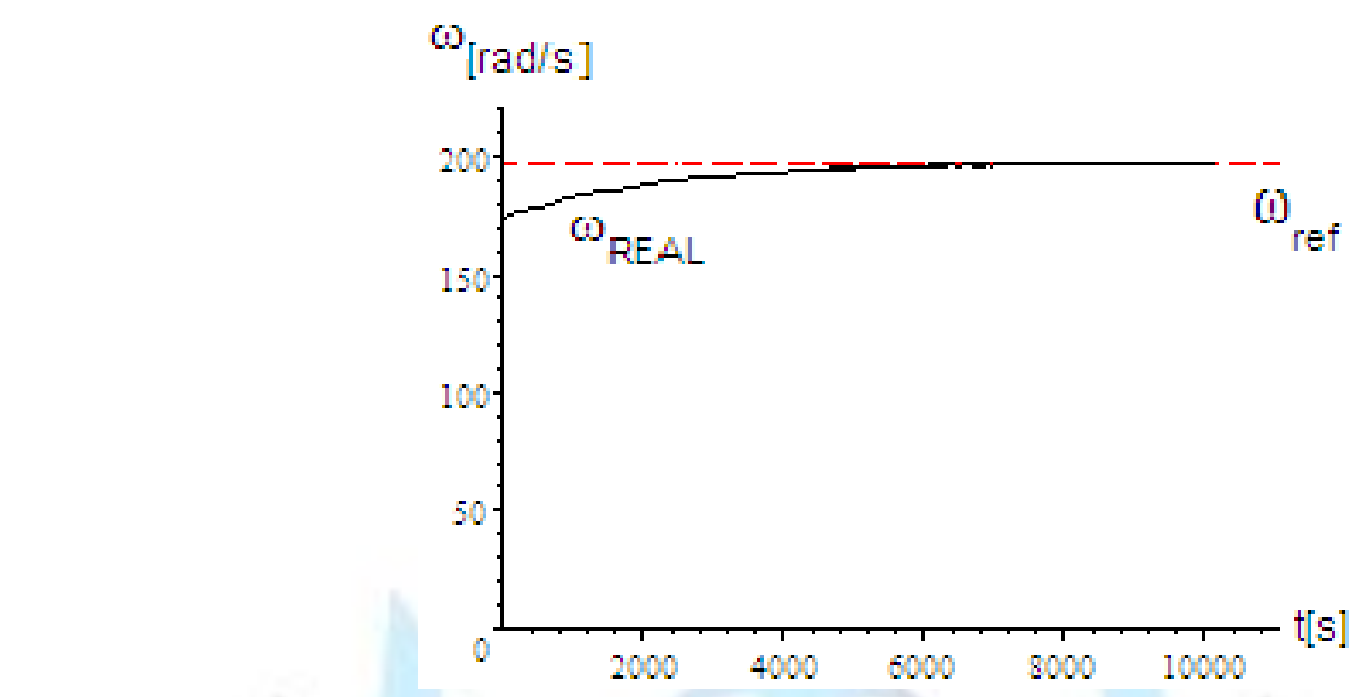

Fig 16: Time variation of $\omega$ at $\omega(0)=174[\mathrm{rad} / \mathrm{s}]$

\section{$\omega_{[\mathrm{rad} / \mathrm{s}]}$}

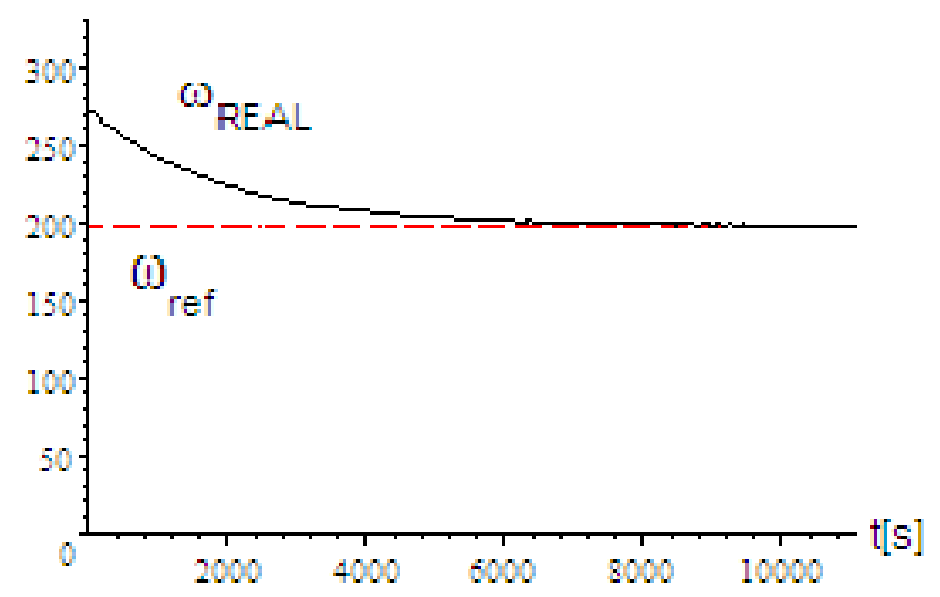

Fig 17: Time variation of $\omega$ at $\omega(0)=274[\mathrm{rad} / \mathrm{s}]$ 


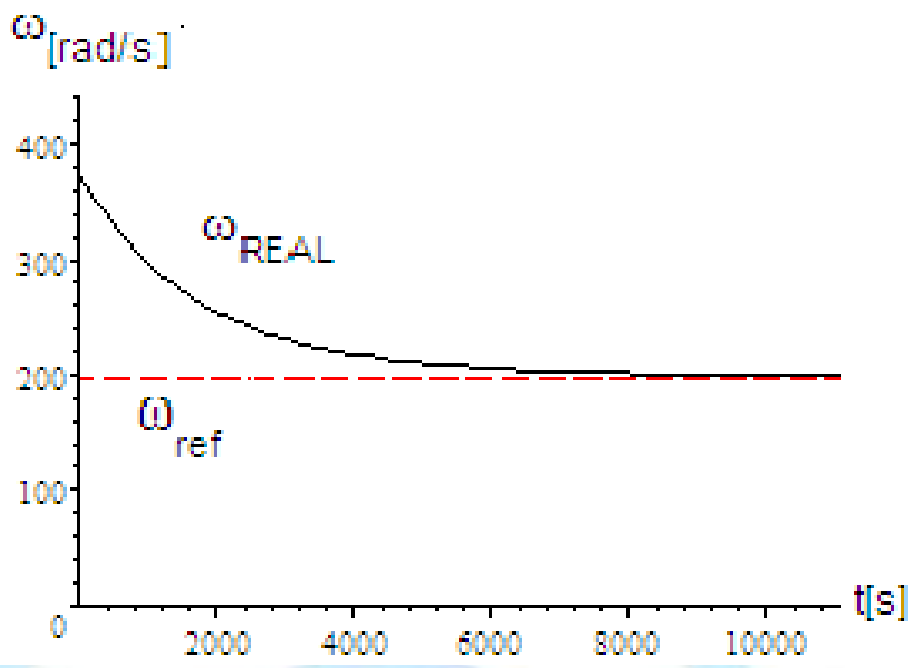

Fig 18: Time variation of $\omega$ at $\omega(0)=374[\mathrm{rad} / \mathrm{s}]$

\section{CONTROL STRUCTURE OF WIND SYSTEM}

The generator load modification is done by the power converters interposed between the turbine and the energy storage block that can be achieved in two basic variants:

- $\quad$ in electrical accumulators (AE), as shown in figure 19;

- $\quad$ in electrical accumulators (AE), super-capacitors (SC), and network, as shown in figure 20.

\subsection{Case of electrical accumulators}

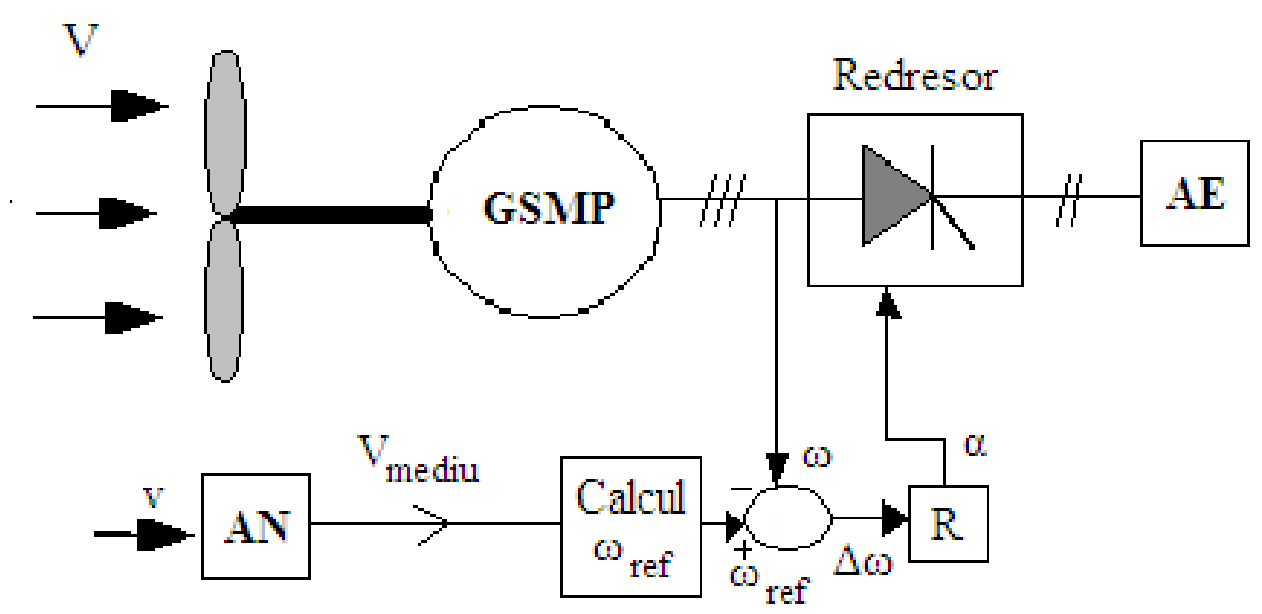

Fig 19: Control the wind system using $\omega_{\text {ref }}$ as reference

The anemometer (AN) can give either average wind speed or instantaneous wind speed, over a time period T, by measuring the speed [14], so it can be calculated the reference RPM using (12). 
$n_{r e f}=\omega_{r e f} \cdot 2 \cdot \pi$

From the generator speed measurement $\omega=2 \cdot \pi \cdot n$ is obtained, and the difference $\Delta \omega=\omega_{\text {ref }}-\omega$ represents the input of controller, as shown in figure 19. The controller $(R)$ modifies the generator load at the output $(\alpha)$ via the thyristors ignition angle of three-phase rectifier [7].

The available maximum wind energy at the wind speed $\mathrm{V}(\mathrm{t})$, in the $\Delta \mathrm{t}$ time interval, is captured by taking the reference speed $\left(\omega_{\text {ref }}\right)$.

\subsection{Case of electrical accumulators, super-capacitors, and network}

Operating at the optimum speed (RPM), $\omega$, is perform by estimating the wind speed using the anemometer (AN) from figure 20 and calculating the $\omega_{\text {ref }}$.

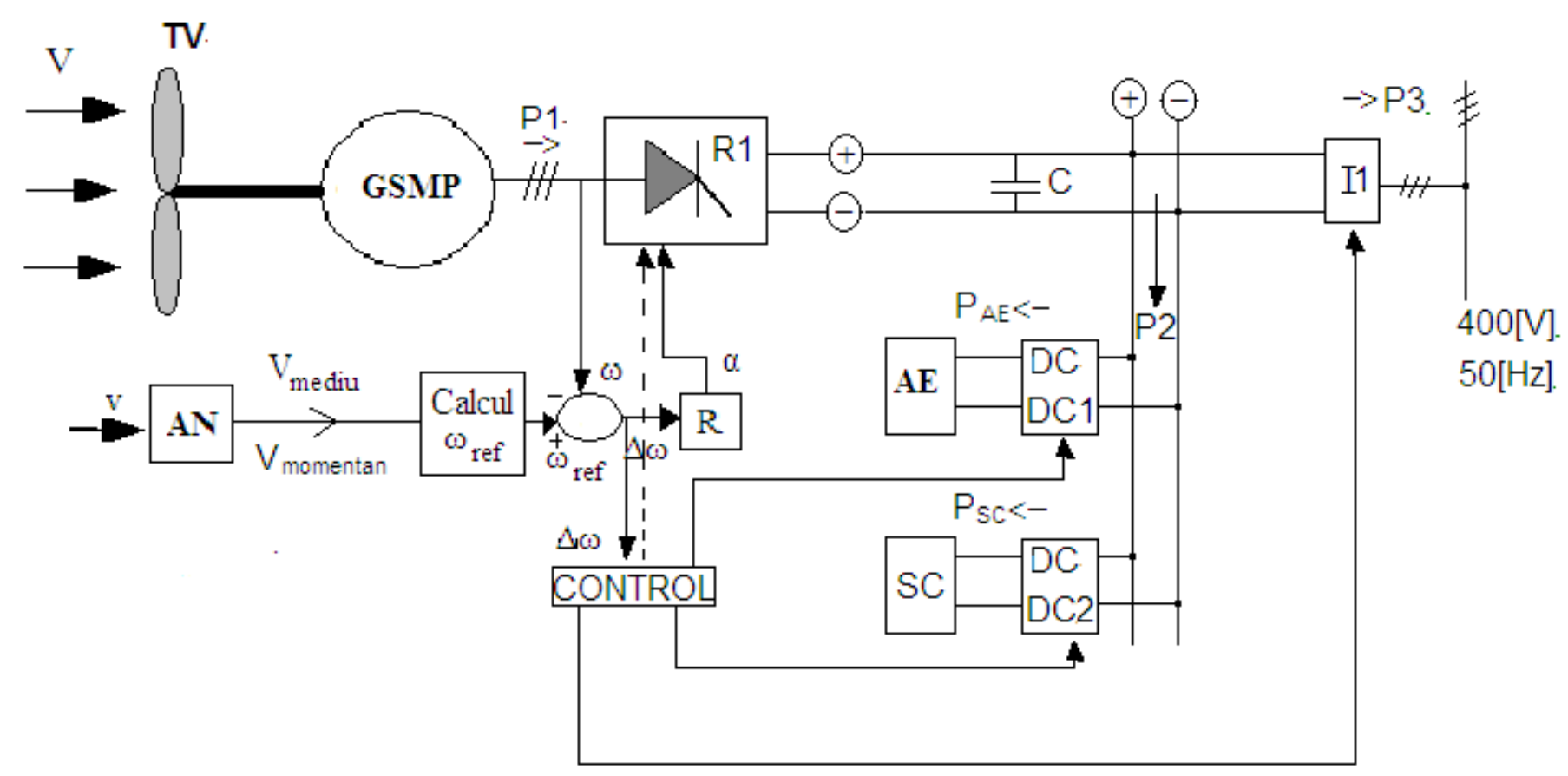

Fig 20: Control the wind system (TV+GSMP)

\subsubsection{The control algorithm}

1. Calculating the mechanical angular speed $\left(\omega_{\text {ref }}\right)$ is based on the mathematical model of wind turbine, by measurement of wind speed, by using the anemometer (AN);

2. By measuring the mechanical angular speed $(\omega)$ from the shaft of the generator, the difference $\Delta \omega=\omega_{\text {ref }}-\omega$, which is the input of controller $(\mathrm{R})$, can be calculated;

3. Using the controller $(\mathrm{R})$, the generator load is changed by the thyristors conduction angle of controlled rectifier (R1);

4. For $\omega=\omega_{\text {ref }}$ a maximum wind energy in a certain time interval is captured, thus the system gives a power $\mathrm{P} 1=\mathrm{P} 2+\mathrm{P} 3$;

5. The power P1 generated by GSMP (permanent magnet synchronous generator) is splitted in two components:

- $\quad \mathrm{P} 2$ - the power given to the storage elements, such as electrical accumulators $A E\left(P_{A E}\right)$ and supercapacitors SC (PS);

- $\quad \mathrm{P} 3$ - the power given to the AC electrical network, by the inverter I1. This power can be hold constant by a positive control of the thyristors conduction angle. 
In this way, the power variation, which is generated by the variable wind speed, can be diminished by storing the power peaks in AE/SC by the proper control of power converters (DC-DC1 and DC-DC2).

\subsubsection{Specifications}

1. The control of rectifier $\mathrm{R} 1$ is achieved by considering the generator RPM.

2. The control of inverter I1 is achieved by maintaining constantly the power P3.

3. The control of both DC-DC1 and DC-DC2 converters is done by considering the power P2=P1-P3 and must follows the time variation of wind speed.

\section{CONCLUSIONS}

Paper shows how many issues involve the time variations of wind speeds.

The mathematical models of both, wind turbine and permanent magnet synchronus generator, allow the optimum RPM determination, such that the maximum captured energy.

By using the original mathematical models of wind turbine and permanent magnet synchronus generator, various operating modes have been simulated, and they were determined the energies obtained in conditions in that the mechanical angular speed was calculated using either instantaneous speed or average speed.

From the above simulations, the following important aspects of the wind system control can be observed:

1. In all the analyzed cases, the prescribed mechanical angular speed $\left(\omega_{\text {ref }}\right)$ for the generator load is achieved in $12200[\mathrm{~s}]$, ie 3.38[h].

2. If the load adjustment is achieved by using a $P$ controller, the mechanical angular speed is accomplished in $3.38[\mathrm{~h}]$ and do not occur overrides.

The initial conditions, which are the mechanical angular speed $\omega(0)$ and the load resistance $R(0)$, by their value, are not significantly influencing the behavior of system, in the sens of occuring the overides or the instabilities of the system controlling, by calculating the generator load as a prescribed value or by using the $\mathrm{P}$ controller that has been provided with the reference size $\omega_{\text {ref }}$.

The control time is by the order of hours and it is ranging between $3[\mathrm{~h}]-5[\mathrm{~h}]$.

The influence of initial conditions on the system dynamics were analyzed and the solutions for reducing the duration of the transient process were proposed.

In this paper two management structures have been presented based on the obtained results.

All contributions presented in this paper are of great importance for both the technical and economical environment, and thus they can be used with confidence in practice, because they are experimental results achieved considering the real problems existing in the technical-economical environment, so they are not theoretically.

\section{REFERENCES}

[1] Babescu M., Borlea I., Jigoria Oprea D., "Fundamental aspects concerning Wind Power System Operattion Part.2, Case Study", Medina Tunisia 2012 IEEE MELECON, 2012,25-28, March978-1-4673-0783-3.

[2] Babescu,M, Borlea I, Jigoria Oprea D "Fundamental aspects concerning Wind Power System Operattion Part.1, Matematical Models", Medina Tunisia 2012 IEEE MELECON, 2012, 25-28 March, 978-1-4673-0783-3.

[3] M. Babescu, O.Gana, L.Clotea, "Fundamental Problems related to the Control of Wind Energy Conversion SystemsMaximum Power Extraction and Smoothing the Power Fluctuations deliveres to the Grid", OPTIM-13th International Conference on Optimizytion of Electrical and Electronic Equipment, Optim 2012, Brasov, 24-26 May.

[4] Babescu M, Borza I., Gana O., Lacatusu F., "Comportarea sistemului electroenergetic eolian la variatii rapide ale vitezei vântului", Producerea, transportul si utilizarea energiei, pp 11-24, Editura RISOPRINT Cluj-Napoca, 2010, ISSN 2066-4125.

[5] Babescu M, Boraci.R, Chioreanu C, Koch C, Gana O, "On Functioning of the Electric Wind System at its Maximum Power”, ICCC-CONTI 2010, Timisoara, Romania, May 27-29, 2010.

[6] Babescu M, Boraci.R, Koch C, Gana O, "The Control of the Diesel - Synchronous Generator Electro-Energetic System", ICCC-CONTI 2010, Timisoara, Romania, May 27-29, 2010.

[7] Bej A., "Turbine de vânt", ISBN 973-625-098-9, Editura POLITEHNICA Timisoara, 2003.

[8] Boldea I., Atanasiu V., -“Analiza unitara a masinilor electrice“, Ed. Academiei RSR, Bucuresti, 1983.

[9] Barakati S.M, M.Kazerani, and J.D.Aplevich, "Maximum Power Tracking Control for a Wind Turbine System Including a Matrix Converter", IEEE Trans. Energy Convers., vol. 24, no. 3, pp.705-713, September, 2009. 
[10] Chen Z.,Spooner E.-“Grid power with variable speed turbines”, IEEE Trans. Power Electron., vol. 16, no. 2, pp. 148154, Jun. 2001.

[11] El Aimani S., Francois B., Minne F., Robyns B.-“Comparativ analysis of control structures for variable speed wind turbine", in Proc. CESA, Lille, France, Jul. 9-11, 2003.

[12] O. Gana, O. Prostean, C. Vasar, M.Babescu -"Modeling and Optimized Control of Photovoltaic Energy Conversion Systems", 7th IEEE International Symposium on Applied Computational Intelligence and Informatics, SACI 2012,2426 May, 978-1-4673-1014-7/12 31.00 2012 IEEE.

[13] Gavris M.L.-“Dual Input DC-DC Converters for Renewable Energy Processing“-Teza de doctorat, feb.2013, Univ."POLITEHNICA" Timisoara.

[14] Gertmar-“Wind turbines“, Berlin, Germany: Springer-Verlag, 2000.

[15] Jiao S., Hunter G., Ramsden V., Patterson D.-“Control system design for a $20 \mathrm{KW}$ wind turbine generator with a boost converter and battery bank load", in Proc. IEEE PESC, Vancouver, BC, Canada, Jun. 2001, pp. 2203-2206.

[16] Luca D., Nichita C., Diop A. P., Dakyo B., Ceanga E.-„Load torque estimators for wind turbines simulators”, in Proc. EPE Conf., Graz, Austria, Sep. 2001, CD-ROM.

[17] Nishikata S, Tatsuta F _"A New Interconnecting Method for Wind Turbine/Generators in a Wind Farm and Basic Performances of the Integrated System -" IEEE Transactions on Industrial Electronics, vol 57, Nr.2,p468-476, ISSN 0278-0046, feb. 2010.

[18] Paunescu D., Babescu M.-“Analiza matematica a dinamicii masinilor electrice-“ Ed. Politehnica Timosoara, 2005.

[19] Petrila D.P._-Energy Conversion and Storage Control for Small Wind Turbine“-Teza de doctorat, feb 2013, Univ."POLITEHNICA" Timisoara.

[20] Petru T.-„Modeling wind turbines for power system studies”, Ph. D. dissertation, Chalmers, Goteborg, Sweden, Jun. 2003.

[21] Quaschning V.-“Understanding Renewable Energy Systems“, ISBN 1-84407-128-6, London Carl Hanser Verlag $\mathrm{GmbH} \&$ Co KG, 2005.

[22] V. D.Müller, O.Gana, L.S.Bocîi, M.Popa, "The leading of the eolian power systems in order to maximise the power and to flatten the fluctuations of the generated power". 